\title{
Revisiting Intrathecal Dorsal Venous Patterns of the Spinal Cord at Thoracolumbar Level as Probable Factor for Post Lumbar Puncture Spinal Hematoma
}

\author{
Arunkumar ARIVALAGAN, Gugapriya TS \\ All India Institute of Medical Sciences, Department of Anatomy, Nagpur, India \\ Corresponding author: Arunkumar ARIVALAGAN arunkumar@aiimsnagpur.edu.in
}

\section{ABSTRACT}

AIM: To evaluate the extrinsic dorsal venous pattern of spinal cord at the thoracolumbar level hypothesizing that any variant of these intrathecal venous pattern as probable factor for post lumbar pucture hemorrhagic complications.

MATERIAL and METHODS: In a tertiary teaching institution, 25 adult cadavers were dissected by standard dissection procedure and spinal cord was removed with meninges. The dorsal aspect was further dissected out and layers of meninges were removed carefully to expose the extrinsic venous system in the dorsal region. The specimens that showed engorged veins were further studied for their extent, pattern, presence of radicular veins, their level and route of exit.

RESULTS: Five specimens showed variant dorsal venous pattern of the extrinsic system of veins in the thoracolumbar region. The main dorsal spinal vein was seen to be engorged, tortuous and more than $2 \mathrm{~mm}$ with engorged radicular veins. Out of 8 engorged radicular veins observed, 6 exited through the dorsal nerve root foramen and 2 exited through a separate foramen.

CONCLUSION: The variant anatomy of intrathecal extrinsic venous system with engorgement of the thoracolumbar region veins might get injured during lumbar puncture procedure. The exit of radicular veins and the dorsal nerve root through the same foramen also makes the veins susceptible to post procedural spinal hematomas.

KEYWORDS: Spinal puncture, Hematoma, Spinal cord, Veins

\section{INTRODUCTION}

S pinal venous drainage has three systems of veins namely intrinsic, extrinsic and extradural (7). Amongst these three interconnected venous systems, the extrinsic venous system of spinal cord is positioned anatomically to encounter traumatic injury during lumbar puncture or spinal anesthesia (Figure 1A, B). Axial pial venous plexus, longitudinal extrinsic venous system and radicular veins constitute this extrinsic system of spinal venous drainage (19).

The longitudinal extrinsic venous system was reported to have an anterior vein, a posterior vein and a "coat hook" shaped radicular vein $(2,23)$. The posterior longitudinal vein had been described to be of smaller caliber in comparison to anterior longitudinal vein (15).

With growing number of surgeries performed with routine use of neuraxial anaesthesia, the reporting of complications like post lumbar puncture hematomas have also increased. Despite the occurrence of consequences that require surgical intervention in $85 \%$ of cases, complications of lumbar puncture had been disregarded considering their lower incidence $(3,8,11)$.

This study revisits the extrinsic dorsal venous pattern of spinal cord at the thoracolumbar level hypothesizing that any variant of these intrathecal venous pattern as probable factor for such post procedural hemorrhagic complications. 


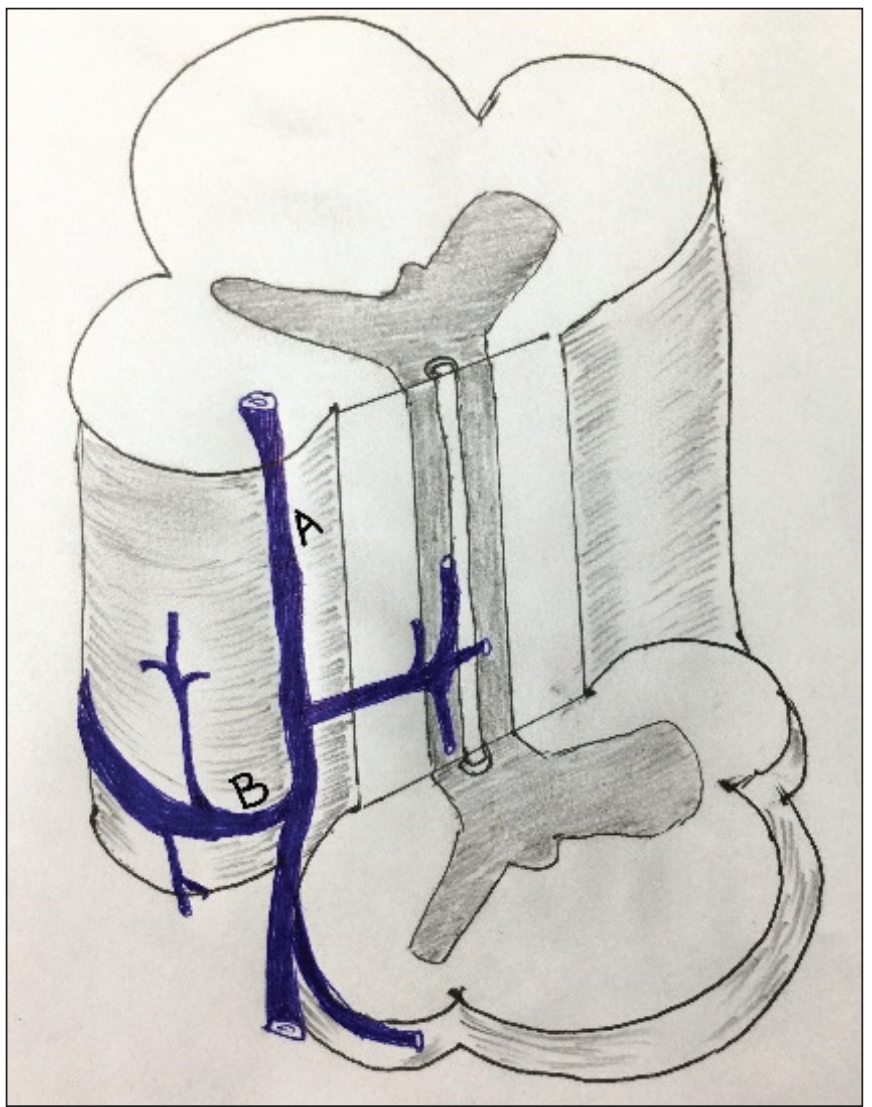

Figure 1: Schematic representation of extrinsic venous system on the dorsal spinal region, A) Longitudinal extrinsic vein B) Radicular vein.

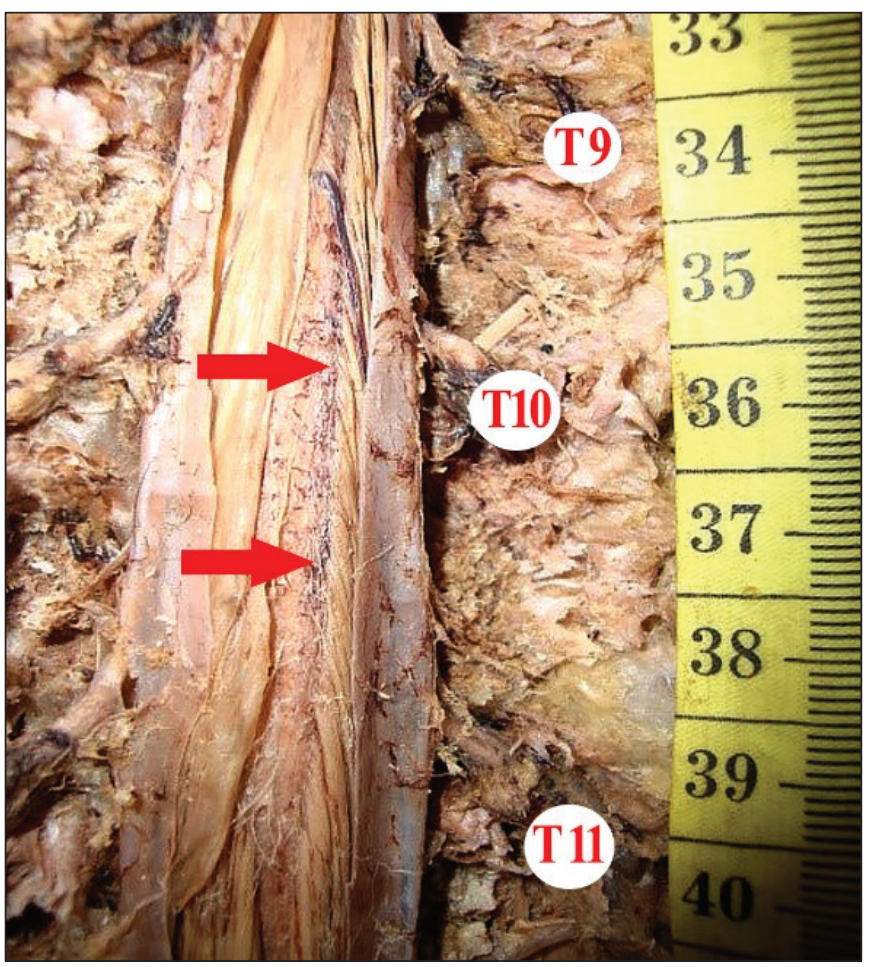

Figure 2: Showing dorsal aspect of spinal cord at thoracolumbar level with slender dark veins filled with clotted blood (red arrows).

\section{MATERIAL and METHODS}

\section{Study Setting}

This cadaveric study was conducted at the government tertiary care teaching hospital at Chennai, Tamilnadu. 25 adult cadavers obtained by regular body donation program and preserved in the Department of Anatomy were used for this study. The sample included 16 males and 9 female cadavers.

Conventional dissection method given in the Cunningham's Manual of Practical Anatomy, Volume Three - Head, Neck and Brain, fifteenth edition, p.no 192 to 202 was used for spinal cord removal. The removed spinal cords with the coverings were stored in a $9 \%$ formalin filled container after providing unique identification number tags.

\section{Study Method}

By incising and reflecting the meningeal layers on the dorsal side, the intrameningeal vasculature was observed. The vessels were categorized and identified into artery and veins based on anatomical descriptions. This study focused on the dorsal veins of spinal cord belonging to the extrinsic venous system. Slender and dark with filled clots was the normal cadaveric appearance of dorsal vein (Figure 2). Such normally appearing spinal cord specimens were excluded from further study. In those specimens that showed dark, fully engorged veins with blood clots, the extent of dilated engorged vessel, the level, branching radicular veins and pattern of exit of the radicular veins were studied. Those veins were subjected to histological evaluation (Figure 3).

\section{Observation}

Out of the 25 specimens of spinal cord studied, $20 \%$ were found to have variant dorsal venous pattern (Figure 4). Two radicular communicating patterns were observed in

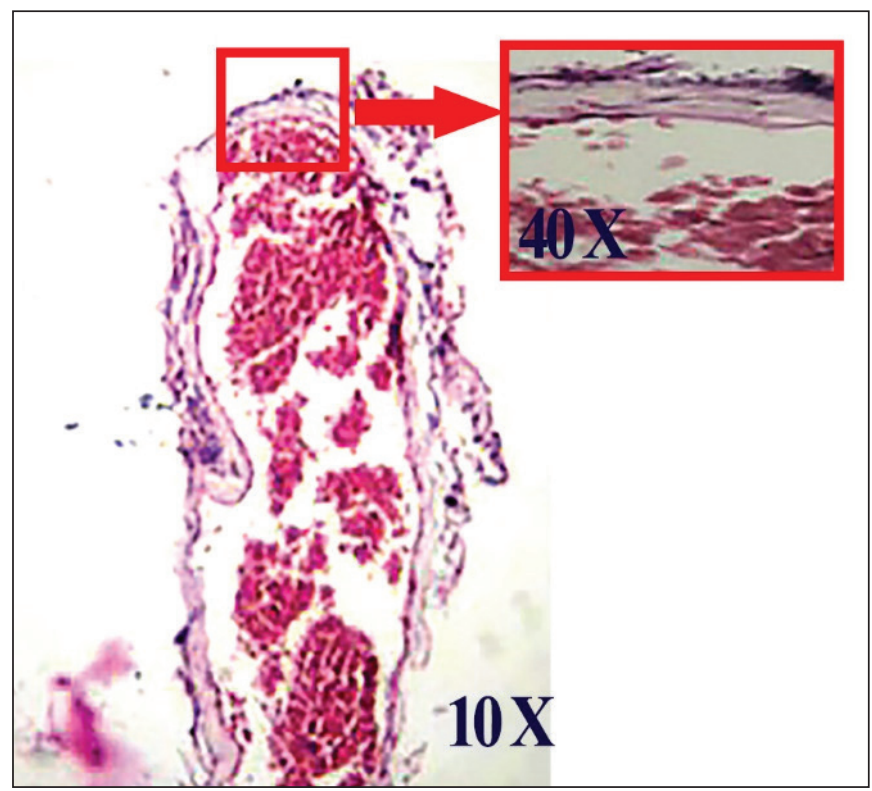

Figure 3: Showing $H$ \& E stained section of a small sized vein under 10X and 40X magnification. 
male cadavers. The other three patterns were observed in specimens of female cadavers. In all 5 specimens, the thoracolumbar segment of the dorsal spinal vein was mainly observed to be dilated and engorged.

A single, engorged and tortuous dorsal spinal vein of $2 \mathrm{~mm}$ thickness extending from conus medullaris to T9 was noted to exhibit radicular communication pattern of extrinsic veins. Two engorged radicular communications on left side were noted at T9 and $L 2$ respectively (Figure $5 A$ ). The $L 2$ level radicular vein exited along with the spinal nerve foramen (Figure 5B), while T9 level radicular vein exited through separate foramen (Figure $5 \mathrm{C)}$.
In another specimen having similar engorged radicular communicating venous pattern, radicular veins were noted in right, left at T9 and L3 respectively (Figure 6A). The T9 exited through a separate foramen (Figure $6 \mathrm{~B}$ ) and $\mathrm{L} 3$ radicular vein along with the dorsal nerve root (Figure 6C).

A specimen showed engorged $2 \mathrm{~mm}$ thick tortuous vein extending from conus medullaris to T9 having an engorged radicular branch with coat hook pattern at the T9 level. The branch exited along with the dorsal nerve foramen (Figure 7).

A loop with coat hook radicular pattern was seen in an engorged, tortuous dorsal vein extending from conus to T10

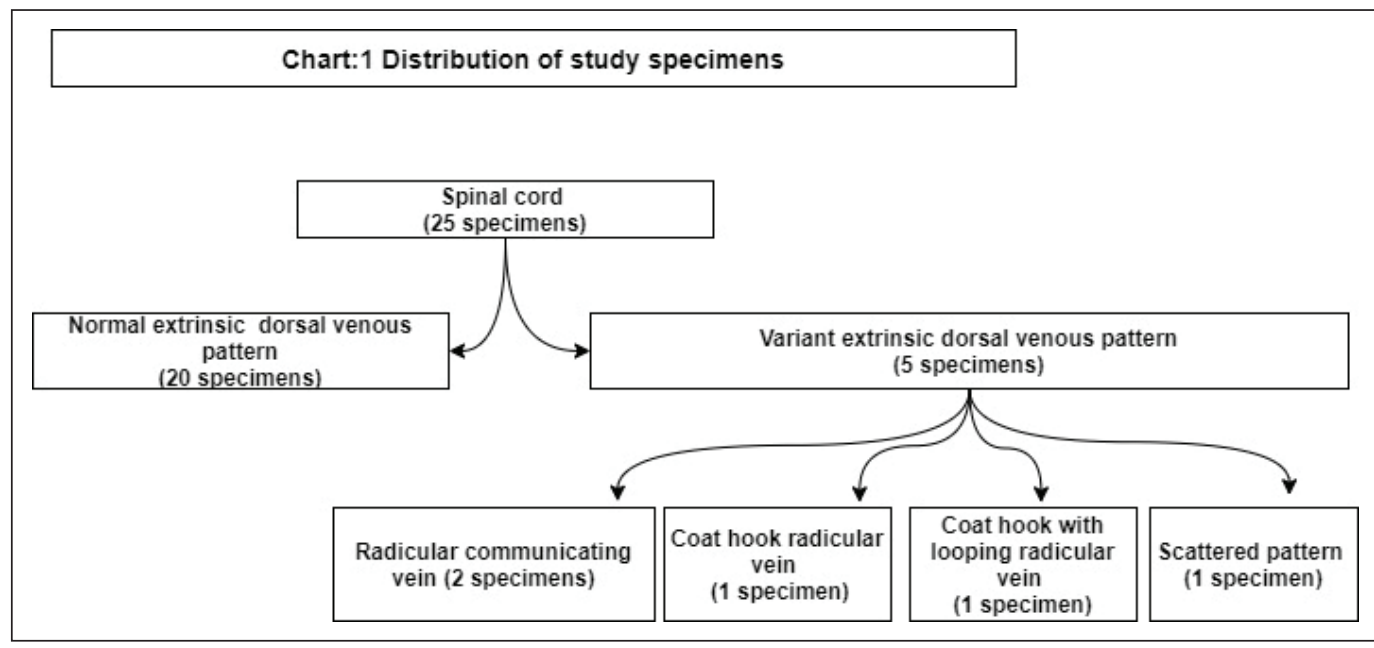

Figure 4: Distribution of study specimens.
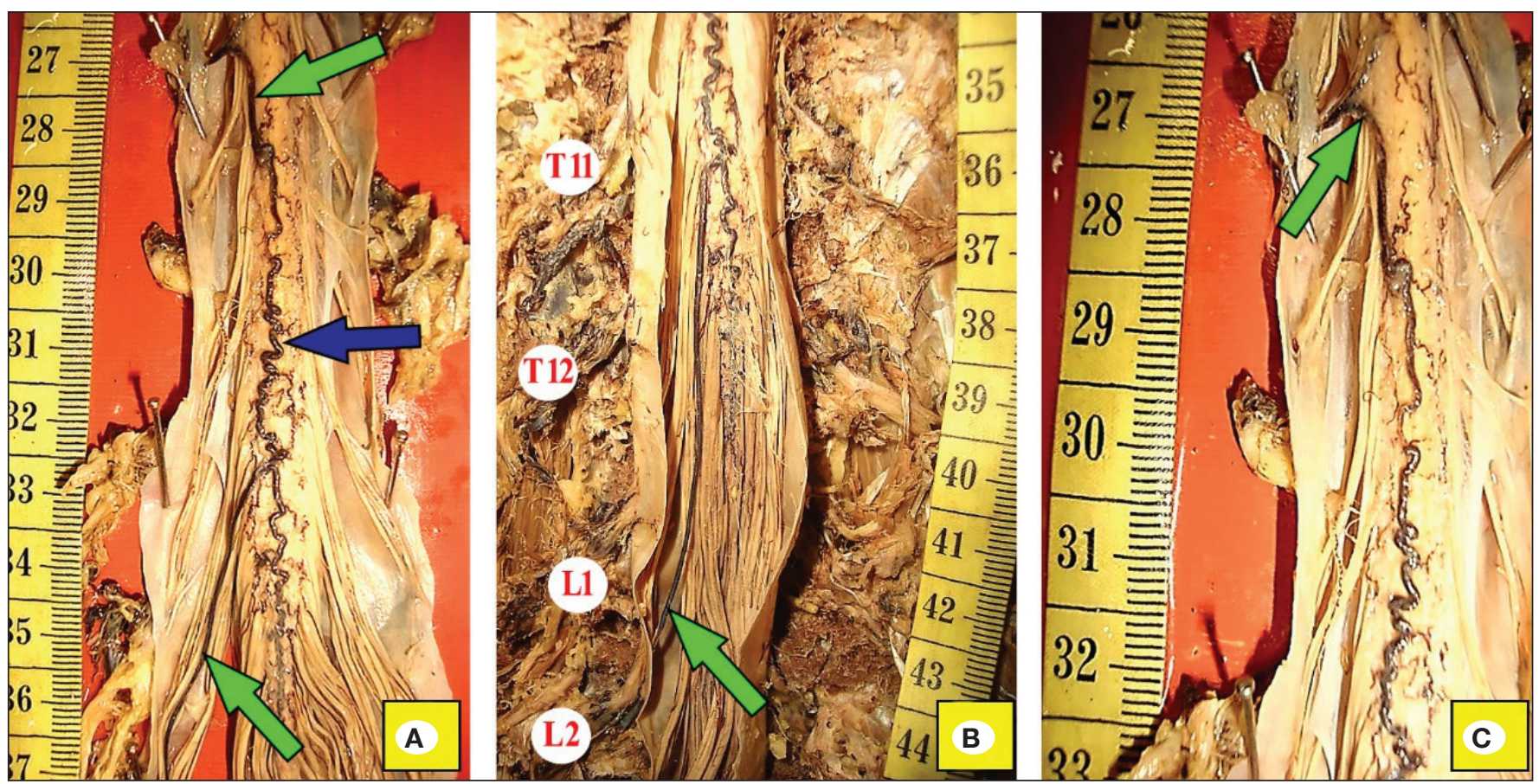

Figure 5: Showing A) a single engorged dorsal vein (blue arrow) and engorged radicular communications at T9, L2 level on left side (green arrow), B) a radicular vein exiting along the dorsal nerve root through same foramen (green arrow), C) a radicular vein exiting through a separate foramen. 
level (Figure 8). The engorged radicular branch was seen to exit along with the spinal nerve root. Multiple slender veins were observed among the rootlets of cauda equina.

Scattered tortuous veins seen between T10-T12 and over conus medullaris were seen in another specimen (Figure 9A). Two engorged radicular branches at T10 and L3 on right side were noted to exit along with dorsal nerve root through the same foramen. Another vein was noted to travel down, parallel to filum terminale (Figure 9B). In the 5 specimens that showed engorged radicular veins, the pattern of exit was observed to be predominantly along with the dorsal nerve root through the same foramen (Table I).

\section{DISCUSSION}

Anatomy text books describe that the spinal veins are located in the piamater and form minute, tortuous venous plexus termed as coronal plexus (21). No single specific pattern had been ascribed by standard textbooks to venous drainage of spinal cord unlike its arterial drainage (16). The finding of engorged vein greater than $2 \mathrm{~mm}$ in the thoracolumbar region in $20 \%$ of specimens in this study contradicts text book description of the small caliber dorsal spinal veins (15).

There exists an accepted architecture for these spinal veins where in the extrinsic venous system was described to be

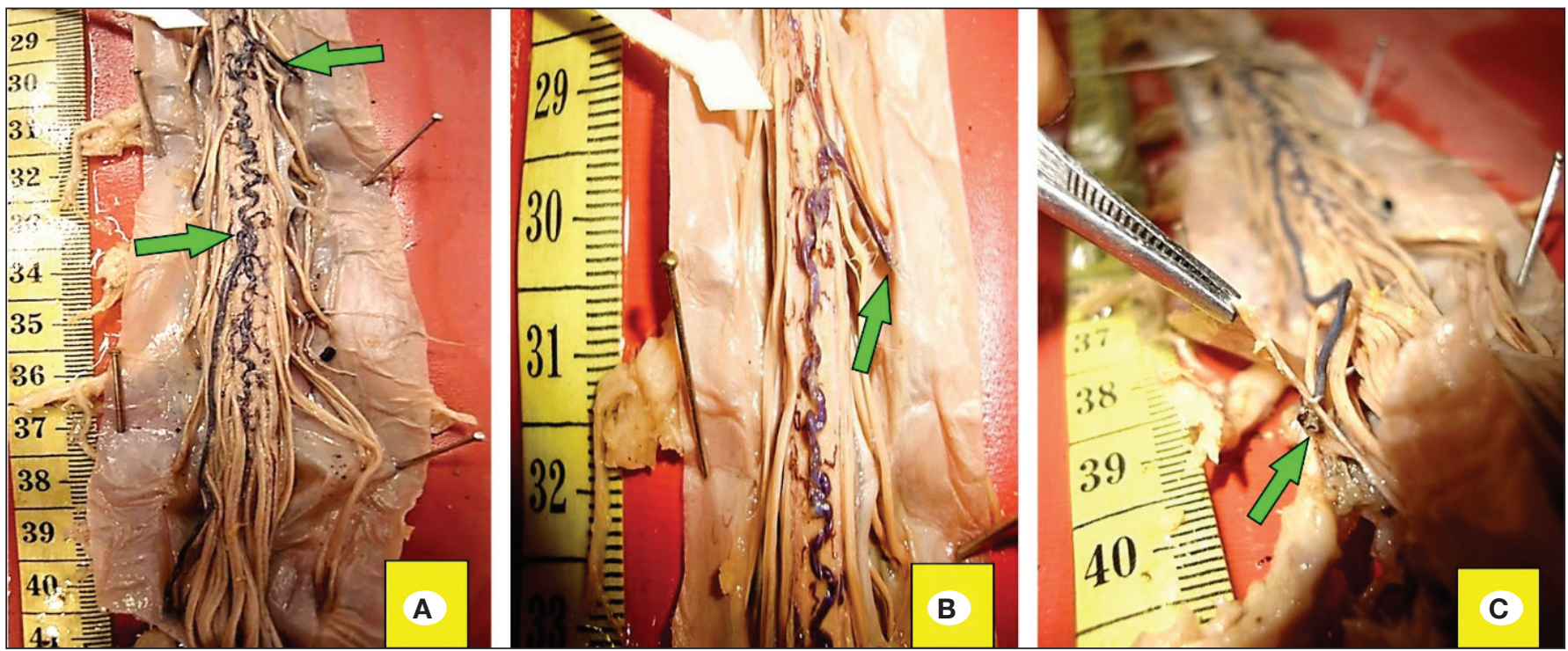

Figure 6: Showing A) A single engorged dorsal vein with right T9, left L3 radicular communication, B) exit of radicular vein through separate foramen, $\mathbf{C}$ ) exit of radicular vein along with dorsal nerve root through same foramen (green arrows).

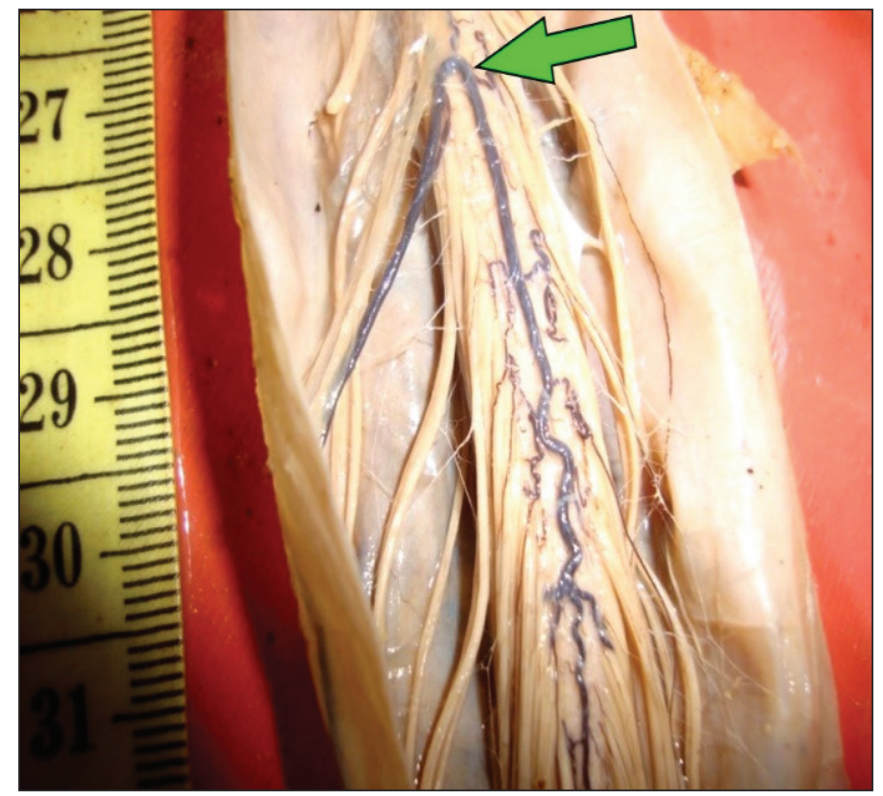

Figure 7: Showing a coat hook engorged radicular pattern in dorsal engorged vein (green arrow).

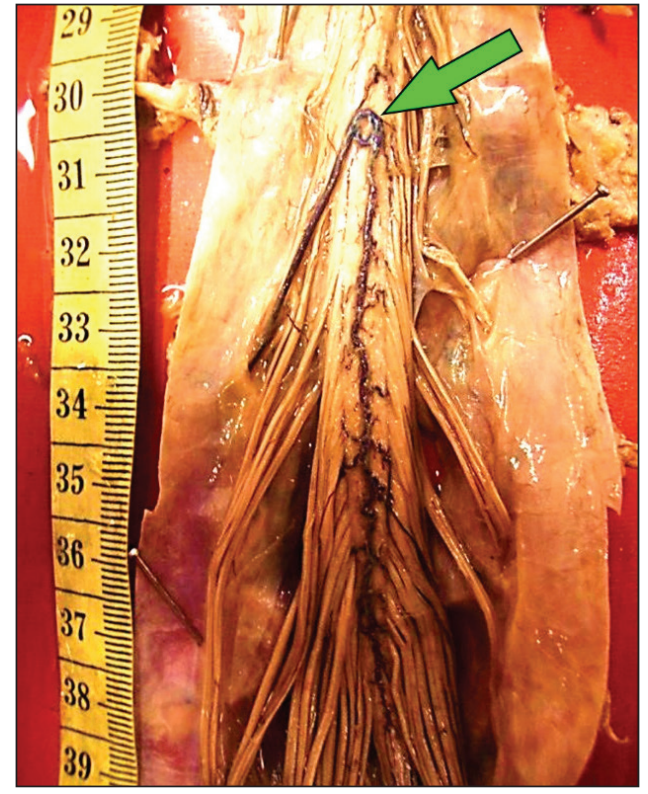

Figure 8: Showing a loop in the coat hook engorged radicular vein (green arrow). 

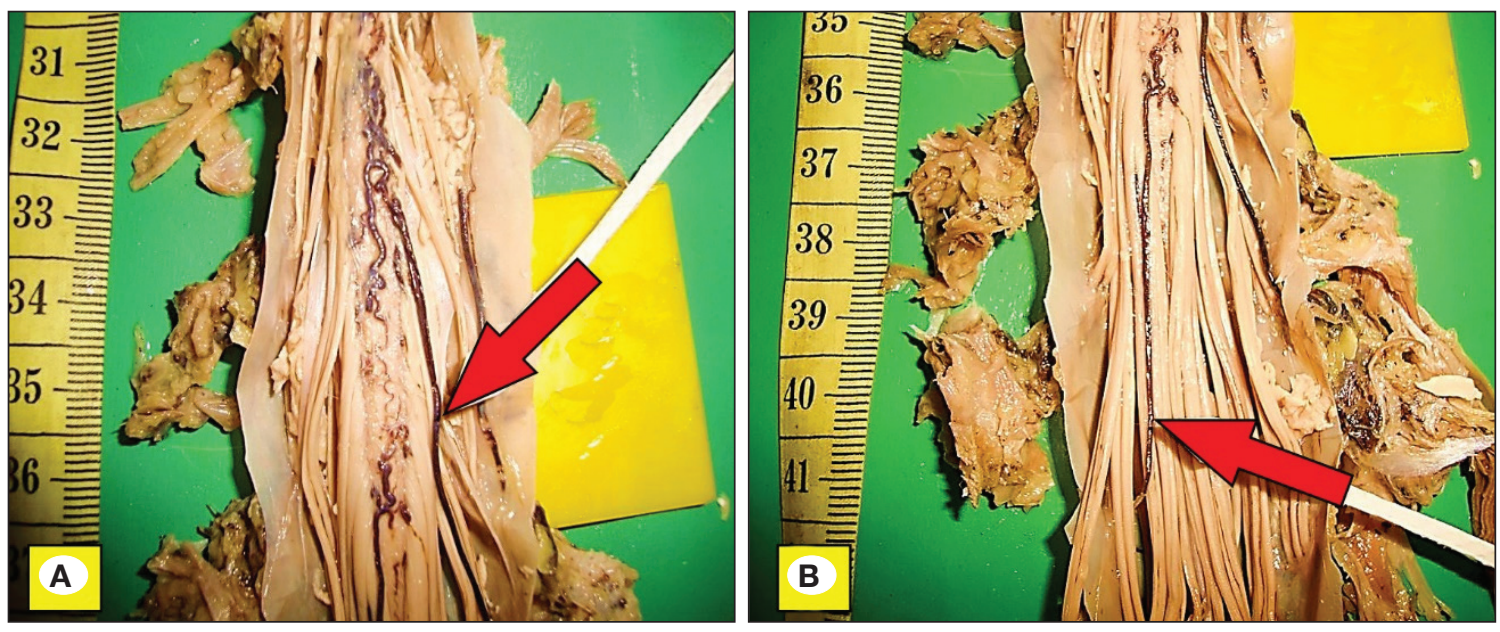

Figure 9: Showing A) scattered dorsal venous pattern with radicular veins, B) a vein travelling parallel to filum terminale (green arrows).

Table I: Pattern of Exit of Engorged Radicular Veins

Total engorged radicular veins observed 8

Total number of radicular veins exiting with nerve root 6

Total number of radicular veins exiting through separate foramen 2

located in the subarachanoid space both in the ventral and dorsal aspect (13).

Among them, the dorsal spinal vein was noted to course from conus medullaris throughout the extent of spinal cord as a single vessel located in the posterior median fissure. Double vessel or plexus had also been noted (20). A set of veins running axially called as "radicular vein" drains these superficial extrinsic veins $(7,13,19,20)$. The route of exit of these radicular veins has been reported either occasionally along with the dorsal nerve root $(7,19,20,22)$ or through a separate foramen located in between the nerve root foramina $(9,12)$. An extensive account of topography of spinal venous drainage in Wistar rats also found single dorsal spinal vein with radicular draining veins that communicate with epimeningeal venous plexus (10).

Even though the variant dorsal venous pattern and the exit of radicular veins as observed in this study stands similar to these previous observations, the engorged vein which was more than $2 \mathrm{~mm}$ and the looping observed in the course of radicular veins were unique findings of our study which might have practical implications.

Lumbar puncture, a seemingly simple day care procedure had been repeatedly reported to result in post procedure complications $(3,8,11)$. The incidence of spinal hematoma post lumbar puncture is unknown. A report claims traumatic injury as the cause in $15.9 \%$ out of $44.9 \%$ cases of post lumbar puncture spinal hematoma (4).

Underlying coagulopathies had been implicated as the reason for such complications by few case reports $(1,3,17,18)$. Nevertheless, the variant venous patterns and engorged venous drainage as seen in this study were implicated as the probable underlying structural basis for such needle site traumatic complications during spinal anesthesia or lumbar puncture $(3,5)$. An autopsy review of such cases of post procedure hematoma had confirmed that the anatomical reason for occurrence of this disastrous complication could be because of needle injury to the radicular vessels travelling along with the segmental nerve in subarachnoid space $(6,14)$. Thus, the present finding of 6 out of 8 engorged radicular veins exiting through same foreman as that of dorsal nerve root stands significant in light of the above report (Table I).

The paucity of literature either on incidence of such radicular veins or their pattern of exit limits the authors from engaging in comparative discussion between present finding and previous studies.

Also, the routine lumbar puncture needs to be given due diligence and preprocedural care considering these structural variants and their possible role in causing postprocedural complications (1).

\section{Limitations of This Study}

The small sample size and nonavailability of pre mortality details about the cadavers used in this study limits the generalizability of the findings. Nevertheless, this study adds on to the basis of the hypothesis that anatomical variants in venous system of spinal cord probably has a role in causing post procedure spinal hematoma which needs further cadaveric and radiological studies.

\section{CONCLUSION}

Occurrence of intrathecal dilated, engorged and tortuous dorsal veins in thoracolumbar region implies that this vein could be injured during lumbar puncture resulting in post procedure spinal hematoma in susceptible individuals. In 
addition, the engorged radicular veins that commonly exit through the same foremen as that of the dorsal spinal nerve roots also need to be considered as causative factor for post procedure hemorrhagic complications.

\section{REFERENCES}

1. Al Jishi A, Murty $\mathrm{N}$ : Massive lumbar spine hematoma postspinal tap. Surg Neurol Int 8:293, 2017

2. Amato ACM, Stolf NAG: Anatomia da circulação medular. J Vasc Bras 14(3):248-252, 2015

3. Brown MW, Yilmaz TS, Kasper EM: latrogenic spinal hematoma as a complication of lumbar puncture: What is the risk and best management plan? Surg Neurol Int 7 Suppl 22:S581-589, 2016

4. Domenicucci M, Ramieri A, Paolini S, Russo N, Occhiogrosso G, Di Biasi C, Delfini R: Spinal subarachnoid hematomas: Our experience and literature review. Acta Neurochir (Wien) 147(7):741-750; discussion 750, 2005

5. Dripps RD, Vandam LD: Hazards of lumbar puncture. J Am Med Assoc 147(12):1118-1121, 1951

6. Edelson RN, Chernik NL, Posner JB: Spinal subdural hematomas complicating lumbar puncture: Occurrence in thrombocytopenic patients. Arch Neurol 31(2):134-137, 1974

7. Griessenauer CJ, Raborn J, Foreman P, Shoja MM, Loukas $M$, Tubbs RS: Venous drainage of the spine and spinal cord: A comprehensive review of its history, embryology, anatomy, physiology, and pathology. Clin Anat 28(1):75-87, 2015

8. Groen RJ, van Alphen HA: Operative treatment of spontaneous spinal epidural hematomas: A study of the factors determining postoperative outcome. Neurosurgery 39(3):494508; discussion 508-509, 1996

9. Huynh TJ, Willinsky RA: Intradural spinal varix: The "doughnut" sign on T2 weighted MR and confirmation with gadoliniumenhanced arterial and blood pool MR angiography. BJR Case Rep 3(1): 20160078, 2016

10. Karmański A, Mikusek J, Karmańska W, Lopata P: External veins of the spinal cord it the Wistar rats. Folia Morphol 54(4):231-241, 1995

11. Kreppel D, Antoniadis G, Seeling W: Spinal hematoma: A literature survey with meta-analysis of 613 patients. Neurosurg Rev 26(1):1-49, 2003
12. Krings $\mathrm{T}$ : Vascular malformations of the spine and spinal cord $^{*}$ : Anatomy, classification, treatment. Clin Neuroradiol 20(1):5-24, 2010

13. Lasjaunias $P$, Berenstein A: Surgical neuroangiography 3: Functional vascular anatomy of brain, spinal cord and spine. Heidelberg: Springer-Verlag, 1990

14. Masdeu JC, Breuer AC, Schoene WC: Spinal subarachnoid hematomas: Clue to a source of bleeding in traumatic lumbar puncture. Neurology 29:872-876, 1979

15. Melissano G, Chiesa R: Advances in imaging of the spinal cord vascular supply and its relationship with paraplegia after aortic interventions. A review. Eur J Vasc Endovasc Surg 38(5):567-577, 2009

16. Miyasaka K, Asano T, Ushikoshi S, Hida K, Koyanagi I: Vascular anatomy of the spinal cord and classification of spinal arteriovenous malformations. Interv Neuroradiol 6 Suppl 1:195-198, 2000

17. Pai SB, Krishna KN, Chandrashekar S: Post lumbar puncture spinal subarachnoid hematoma causing paraplegia: A short report. Neurol India 50(3):367, 2002

18. Park JH, Kim JY: latrogenic spinal subarachnoid hematoma after diagnostic lumbar puncture. Korean J Spine 14(4):158161,2017

19. Santillan A, Nacarino V, Greenberg E, Riina HA, Gobin YP, Patsalides A: Vascular anatomy of the spinal cord. J Neurointerventional Surg 4(1):67-74, 2012

20. Sliwa JA, Maclean IC: Ischemic myelopathy: A review of spinal vasculature and related clinical syndromes. Arch Phys Med Rehabil 73(4):365-372, 1992

21. Standring S: Gray's Anatomy, The Anatomical Basis of Clinical Practice, $41^{\text {st }}$ ed, Elsevier, 2015:770

22. Tadié $M$, Hemet J, Freger $P$, Clavier E, Creissard P: Morphological and functional anatomy of spinal cord veins. J Neuroradiol 12(1):3-20, 1985

23. Takase K, Akasaka J, Sawamura Y, Ota H, Sato A, Yamada T, Higano S, Igarashi K, Chiba Y, Takahashi S: Preoperative MDCT evaluation of the artery of Adamkiewicz and its origin. J Comput Assist Tomogr 30(5):716-722, 2006 